\title{
Jóvenes emprendedores y sus proyectos de Comunicación en la red: estudio de caso de Periodistas en potencia y Portal del Sur
}

\author{
Jesús Segarra Saavedra \\ Universidad de Alicante \\ Patricia Páramo Galdón \\ Diario Información de Alicante \\ Belén Puebla Martínez \\ Universidad Rey Juan Carlos
}

\section{Palabras clave}

Estudiantes de comunicación, periodistas, proyectos de comunicación, formación

\section{Resumen}

La situación de crisis económica en la que vivimos ha generado que los profesionales de la comunicación deban emprender nuevas iniciativas para poner en marcha y desarrollar sus propios proyectos laborales. Internet permite desarrollar estas iniciativas de una forma autónoma. Este hecho ayuda a que los jóvenes universitarios de comunicación, enfrentados a un escenario tan precario al finalizar sus estudios, se decanten por crear su propia empresa y comenzar así una experiencia de microperiodismo con sus compañeros. Se trata de un cambio de roles integral. En lugar de buscar/encontrar un trabajo donde están supervisados por profesionales con más experiencia, se convierten en sus propios jefes adquiriendo y poniendo en práctica las funciones de periodistas y empresarios simultáneamente. Es el caso de Periodistas en Potencia ${ }^{1}$ (portal de reportajes audiovisuales especializados en temática cultural) y de Portal del Sur ${ }^{2}$ (página web dedicada a la actualidad de los municipios del nudo sur de Madrid). Dos proyectos desarrollados en la red realizados por alumnos y ex alumnos de periodismo y de comunicación audiovisual de la Universidad Rey Juan Carlos de Madrid. Para este artículo se realiza un análisis de contenido de los portales mencionados, así como entrevistas en profundidad a los creadores de las webs, con el fin de conocer las experiencias formativas de estos periodistas recién graduados y las nuevas tendencias del mercado laboral y microempresarial. Por tanto, el problema de investigación se

\footnotetext{
1 Desde ahora PEP.

2 A partir de ahora PDS.
} 
centra tanto en los productos como en los periodistas que los crean. Los resultados mostrarán las necesidades formativas que estos estudiantes de periodismo y jóvenes emprendedores han detectado en su incursión en el mundo laboral.

\title{
Young businessmen and their web communication projects: a case study of Periodistas en Potencia and Portal del Sur.
}

\section{Keywords}

Communication students, journalist, communication projects, training

\begin{abstract}
The economic crisis in which we live has meant that Communication professionals must undertake new initiatives to launch and develop their own work projects. Internet allows the development of such initiatives independently. This helps university students in Communication, faced with an scenario so precarious after graduation, opt for starting their own business and begin a microjournalism experience with partners. This is a complete reversal role. Instead of looking for / finding a job where they are supervised by more accomplished professionals, they become their own boss by purchasing and implementing the roles of journalists and businessmen simultaneously. We refer to 'Periodistas en Potencia' (audiovisual reports portal which is specialized in cultural issues) and 'Portal del Sur' (website about current information of the municipalities node south of Madrid), two network projects made by students and former students of Journalism and Audiovisual Communication at the 'Universidad Rey Juan Carlos de Madrid'. This article is based on a content analysis from the websites before mentioned, and in depth interviews with the websites creators. It allows a wide knowledge about the formative experiences of these journalists graduates, labour market trends and microenterprise. Therefore, the research question focuses on both the products and the journalists who create them. The results show that these training needs of journalism students and young businessmen have been detected in its foray into the world of work.
\end{abstract}

\footnotetext{
Autores

Jesús Segarra [jesus.segarra@ua.es] es licenciado en Publicidad y Relaciones Públicas, D.E.A. y actualmente doctorando de la Universidad de Alicante. Profesionalmente colabora en distintos proyectos de investigación de comunicación COMPUBES (Comunicación y Públicos Específicos de la UA), LUDICOM (Instituto AIJU y UA), Redes de Investigación en Docencia Universitaria CREACOM (UA) y VISUAL Investigando la Comunicación en España (URJC).
} 
Patricia Páramo [pparamo@epi.es] es licenciada en Publicidad y Relaciones Públicas por la Universidad de Alicante, licenciada en Periodismo y máster en Técnicas Avanzadas en Comunicación por la Universidad de Murcia. Tras su paso por prensa, radio y televisión actualmente trabaja en la web del Diario Información de Alicante, medio con mayor difusión en la provincia.

Belén Puebla [belen.puebla@urjc.es] es profesora visitante de Periodismo y Comunicación Audiovisual del departamento de Comunicación II de la Universidad Rey Juan Carlos de Madrid. Licenciada en Periodismo y en Comunicación Audiovisual y DEA por la URJC. Completó su formación con el Master de Comunicación y problemas socioculturales. Ha participado en diversos proyectos de investigación de la URJC. En la actualidad está finalizando su tesis doctoral El tratamiento de la actualidad en las series de ficción españolas: los casos de 7 vidas y Aquí no hay quien viva. Es co-fundadora y coordinadora general de la Revista Científica en Comunicación Aplicada Index.Comunicación de la URJC. 


\section{Introducción}

La universidad forma a profesionales libres y autónomos con capacidad para aprender y adaptarse a los cambios. El mercado laboral los incorpora sometiéndolos a duras condiciones laborales. El desempleo agudiza el sometimiento e impide incorporar a la ingente cantidad de nuevos egresados en Comunicación.

La situación de crisis actual económica y financiera lleva asociada un descenso de ingresos publicitarios para medios y soportes. Esto origina una reducción de los costes de personal y un paralelo incremento en la plantilla de colaboradores esporádicos y becarios en proceso de formación, principalmente en los períodos vacacionales de la plantilla fija o habitual. Lo que en principio llevaría a una profesionalización de los becarios y a un incremento en sus conocimientos prácticos, a día de hoy sólo se ha convertido en un punto y seguido, ya que éstos siguen denunciando su explotación y la escasa formación recibida por parte de las empresas.

Abrimos un debate: ¿es eficaz, adecuada, actual y dinámica la formación universitaria?

El presente artículo pretende conocer la situación de los egresados en Comunicación, las demandas del sector, su inserción al mercado laboral, el tiempo que tardan en incorporarse y qué medios de comunicación, empresas o instituciones contratan a estos egresados así como la formación requerida, tipo de contrato y sueldo. Conocer las lagunas e insuficiencias formativas es otro de los objetivos así como descubrir las estrategias que siguen estos jóvenes en su camino hacia la consecución de un empleo.

Para llegar a esta meta seguiremos un esquema que contextualice al lector con el ciclo de vida del estudiante de Comunicación en su transición hacia su dedicación profesional.

\section{La formación en Comunicación}

Según el Instituto Nacional de Estadística (INE), el número de universidades públicas y privadas donde se imparte alguno de los estudios de Ciencias de la Información (CCI) -Periodismo (P), Comunicación Audiovisual (CA) y/o Publicidad y Relaciones Públicas (PyRRPP)-en España son 109:

Tabla 1. Centros públicos y privados que imparten alguno de los estudios de CCI durante el curso 2010-2011

\begin{tabular}{|l|c|c|c|}
\hline & P & CA & PyRRPP \\
\hline Universidades públicas & 16 & 24 & 19 \\
\hline Universidades privadas & 17 & 16 & 16 \\
\hline Total & 33 & 40 & 35 \\
\hline
\end{tabular}

Fuente: elaboración propia a partir de los resultados del INE. 
Por otro lado, según el Libro Blanco: Títulos de Grado en Comunicación (ANECA, 2004: 106) «de las 17 comunidades autónomas que conforman el Estado español, 11 cuentan con centros en los que se ofertan estudios de comunicación. En concreto, Cataluña (11), Madrid (8), Valencia (5), Castilla-León (5), Galicia (3), Andalucía (2), Murcia (2), País Vasco (1), Navarra (1), Extremadura (1) y Canarias (1)» aunque desde entonces se han incorporado nuevos planes de estudio en otras regiones españolas. Aún así, vemos como Madrid y Cataluña concentran las principales canteras de egresados en Comunicación.

Si profundizamos en la variable sexo, los datos del alumnado matriculado por género y estudio nos muestran que son más mujeres que hombres las estudian alguno de los grados en Comunicación.

Tabla 2. Alumnado matriculado en el curso 2010-2011 en estudios de CCI por sexo

\begin{tabular}{|l|c|c|c|}
\hline & P & CA & PyRRPP \\
\hline Hombres & 4.655 & 3.801 & 3.440 \\
\hline Mujeres & 7.579 & 4.774 & 7.923 \\
\hline TOTAL & 12.234 & 8.575 & 11.363 \\
\hline
\end{tabular}

Fuente: elaboración propia a partir de los resultados del INE.

Y si tenemos en cuenta el número de alumnos que finaliza su período universitario -licenciatura/grado-, podemos observar que desde que comenzara la crisis, allá por 2008, han terminado alguno de los estudios de Ciencias de la Información 30.791 personas ${ }^{3}$.

Tabla 3. Alumnos en valores absolutos que han finalizado estudios de CCI en España durante la crisis

\begin{tabular}{|l|c|c|c|c|c|}
\hline Curso académico & $2007 / 08$ & $2008 / 09$ & $2009 / 10$ & $2010 / 11$ & TOTAL \\
\hline CCI & 7.441 & 7.771 & 8.061 & 7.518 & 30.791 \\
\hline $\begin{array}{l}\text { Alumnado que } \\
\text { terminó los estudios }\end{array}$ & 78.520 & 79.802 & 79.396 & 82.864 & 320.582 \\
\hline
\end{tabular}

Fuente: elaboración propia a partir de los resultados del INE.

Si aún en condiciones normales resulta difícil que el mercado laboral asuma tal cantidad de personas, con la crisis, la situación empeora cuando ni siquiera pueden dedicarse a otra profesión en la que han invertido como poco, cuatro años de su vida.

No obstante, el mercado laboral considera que «la formación universitaria es insuficiente. En general, los profesionales del mundo del periodismo creen que la formación recibida en las facultades es inadecuada y no se ajusta a las necesidades reales que exige la profesión» (Caro González y Jiménez Marín, 2006: 313). Esto no significa que nuestras opiniones coincidan con quienes «cuestio-

3 La Asociación de la Prensa de Madrid (APM) estima en su informe del 2011 que se han licenciado 75.346 periodistas desde la creación de la carrera en España. 
nan a día de hoy la necesidad de formación universitaria en Periodismo, lo que desprestigia la profesión» (Caro González y Jiménez Marín, 2006: 313-314). Muy al contrario. Apostamos por una formación universitaria de calidad de los nuevos egresados y por un camino hacia su primera experiencia laboral enriquecedor a través de colaboraciones, prácticas formativas de calidad, acordes a su situación laboral y bajo una supervisión, además de otros procesos de formación de posgrado, cursos de especialización, así como de iniciativas propias como colaboraciones en otros medios y soportes, blogs personales y del asociacionismo emprendedor.

Continuando con las demandas del sector empresarial, y según un estudio realizado por la Facultad de Ciencias de la Comunicación de Santiago de Compostela en 2004, entre las actitudes y habilidades más valoradas por sus superiores, según los licenciados en Periodismo destacan la rapidez, la buena redacción, el dominio de las nuevas tecnologías o la identificación con la línea editorial de la empresa. En último lugar se encuentra la proposición de nuevos enfoques a temas asignados. Estas informaciones contrastan claramente con lo expuesto por Caro González y Jiménez Marín (2006) respecto a las enseñanzas impartidas por las universidades y a su afán por formar profesionales con espíritu crítico. A juzgar por estos datos, las empresas prefieren que los periodistas recién licenciados lleguen con los conocimientos necesarios para desarrollar su trabajo pero siguiendo las directrices marcadas por la directiva, por lo que la opinión propia y el espíritu crítico no son vistos de manera muy positiva.

De esta forma, si contraponemos las fortalezas «los conocimientos teóricos; la aptitud para aprender; la informática y las nuevas tecnologías, y la capacidad de análisis» con las debilidades "carencia de formación práctica, de habilidades directivas, de capacidad para comunicarse eficazmente, de manejo de los idiomas y de aptitud para trabajar en equipo» (Pérez de Pablos, 2005: web) y si tenemos en cuenta la situación de desempleo actual, observamos como el camino hacia el empleo es duro aunque los hay que están tomando medidas para hacer de su tiempo una inversión de futuro, utilizando para ello las nuevas tecnologías de la información.

\section{La transición de la universidad hacia la empresa pasando por la empren- deduría}

Finalizar una carrera universitaria no supone una garantía de conseguir inmediatamente un trabajo en el que los recién egresados puedan aplicar los conocimientos académicos y prácticos adquiridos a lo largo de cuatro años de formación, y mucho menos hacerlo con una remuneración acorde al nivel de estudios adquirido. «Los recién licenciados en periodismo se encuentran con un entorno profesional nada complaciente, al que resulta bastante fácil acceder, y cuyas condiciones laborales son bastante precarias. Los sueldos, en general, son bajos, y la inestabilidad es bastante elevada» (Caro González y Jiménez Marín, 2006: 323). 
Por todos es sabido que hay jóvenes graduados españoles que aun contando con su carrera universitaria se ven obligados a desempeñar actividades no relacionadas con su formación académica. En 2002 el porcentaje de licenciados en Periodismo que se dedicaban a tareas relacionadas con tareas administrativas alcanzaba una tasa del $8,1 \%$, mientras que un $5,4 \%$ se veían abocados a realizar labores de dependientes o vendedores (Bancaja, 2002: 7). Diez años después esta realidad no ha hecho más que acentuarse y disparar la proporción de periodistas que no pueden ejercer como tales y recibir a cambio una contraprestación económica que les permita subsistir dignamente. Según el Informe anual de la profesión periodística 2011 editado por la Asociación de la Prensa de Madrid (APM) sólo uno de cada dos licenciados en Periodismo encuentra trabajo en el sector.

Así las cosas, los recién egresados se encuentran con un gran dilema: conformarse con lograr un trabajo no relacionado con sus estudios, pero que les permita sobrevivir -opción elegida por una minoría como se señala en el párrafo anterior- o luchar por abrirse paso en el universo mediático, aunque esto suponga en muchos casos trabajar gratis y en condiciones precarias. Los que optan por la segunda opción cuentan con varias posibilidades para llevarla a cabo. Muchos ejercen como becarios o realizan prácticas en empresas periodísticas. La diferencia con otras titulaciones es que, una vez terminada la carrera, el becario sigue realizando prácticas durante varios años.

El proceso de aprendizaje continúa. Cambia el dónde y el cómo. Las aulas ceden el paso a las redacciones y los periodistas en activo de las empresas absorben el rol de profesores. Ésta es para muchos la única forma de darse a conocer dentro de las empresas en las que aspiran a ejercer su labor periodística. Y es que tal y como señala (Pérez de Pablos, 2005: web) «las aptitudes que demandan las empresas de los titulados universitarios no coinciden con las que llegan a las entrevistas de trabajo». Por esta razón, las empresas gustan de formar a su estilo y conveniencia a una gran cantidad de recién licenciados para luego elegir entre los que destaquen a los periodistas que formarán parte de su plantilla en un futuro. La promesa de una nómina y un trabajo estable en una institución periodística de prestigio hace que muchos jóvenes aguanten situaciones, que distan mucho de las prácticas de buena ética que deberían seguir las empresas.

Este panorama puede llegar a generar situaciones de precariedad laboral tan destacables como la detectada este mismo año en el diario El País. El rotativo podría ser sancionado con 100.000 euros tras una inspección de Trabajo por las condiciones laborales de sus becarios quienes llevaban turnos de noche y fin de semana sin supervisión, cobraban entre 700 y 800 euros mensuales y realizaban tareas de responsabilidad que no correspondían a su condición laboral ${ }^{4}$.

Sin embargo, esta situación no es nueva ya que Bel (2004: 306) opinaba a principios de la pasada década que «el sector está sumido en precariedad laboral por la elevada tasa de paro, la falta de regulación y las trampas legales existentes,

4 Información obtenida de http://www.equiposytalento.com/noticias/2012/02/13/el-pais-sancionado-por-las-condicioneslaborales-de-sus-becarios. 
que permiten a las empresas contar con una legión de periodistas dispuestos a firmar contratos temporales en condiciones leoninas» (cit. en Caro González y Jiménez Marín 2006: 323).

Así las cosas, otros optan por constituirse como periodistas freelance, aunque los datos recogidos con respecto al autoempleo por la (Agencia Nacional de Evaluación de la Calidad y la Acreditación (ANECA), constatan que tiene poco peso en la profesión periodística. En Galicia, el porcentaje de autoempleados no alcanza el 3\%, mientras que en el resto de España, según la encuesta CHEERS ${ }^{5}$, el tanto por ciento sigue siendo muy bajo, de un $6 \%$, en comparación con otras profesiones, como es el caso de los arquitectos, que en el 72,6\% de los casos son trabajadores por cuenta propia.

En relación al autoempleo, los casos objeto de estudio en este artículo son un claro ejemplo de la visión emprendedora de los recién egresados en Periodismo, así como de la inclusión de pequeñas empresas periodísticas independientes (que no pertenecen a un gran grupo editorial) en el universo mediático actual. Así, PEP y PDS contradicen de forma fehaciente la opinión de Caro González y Jiménez Marín (2006: 321), que en su artículo «Periodistas: El acceso al mercado laboral» señalaban que «los licenciados en Periodismo carecen de espíritu emprendedor, lo que puede ser debido a una escasa formación empresarial. Además, la estructura de las empresas de comunicación impide la incorporación al sector de nuevas empresas si no es formando parte de los grandes grupos existentes». No obstante, a la hora de contraponer ambas realidades, hay que tener en cuenta que las circunstancias actuales han variado con respecto al año 2006, fecha del estudio de Caro González y Jiménez Marín. Seis años de diferencia en el que si bien las condiciones del mercado laboral para los profesionales de la comunicación que acaban de salir de la universidad no han experimentado una notable evolución, sí lo ha hecho un nuevo medio, por entonces emergente y ahora ya afianzado: Internet. Las Tecnologías de la Información y la Comunicación (TIC) han supuesto una gran revolución en el universo mediático. La inmediatez, la capacidad para llegar a una audiencia muy amplia y heterogénea, la facilidad de los usuarios para acceder a la información y el reducido coste que supone publicar en la red son sólo algunas de las características definitorias de este medio. Cualidades que asimismo han hecho posible que proyectos periodísticos como los estudiados hayan visto la luz.

De este modo, tanto PEP como PDS recrean a la perfección lo que para estos autores suponía un gran reto seis años atrás. Ahora son los propios egresados los que a través de su «iniciativa emprendedora dinamizan el sector aportando una oferta atractiva» (Caro González y Jiménez Marín, 2006: 321). Al hilo de los casos estudiados encontramos Hoopshype, el proyecto de microperiodismo de mayor éxito en nuestro país. Fue fundado por Javier Sierra junto a otro pe-

5 Un grupo de investigadores de once países europeos y Japón en 1997 crearon el Career after Higher Education: a European Research Study (CHEERS) que pretende estudiar cuáles son las relaciones entre el capital humano y las necesidades de empleo del tejido empresarial. 
riodista y un webmaster en 2002. Está escrito en inglés y trata sobre baloncesto americano $^{6}$.

De esta forma, cabe destacar el papel fundamental de Internet para los nuevos periodistas en la etapa de transición, desde la formación universitaria a su incursión como trabajadores reconocidos y remunerados como tales en un medio de comunicación. Tal y como destacan Domínguez Marín y Pérez Colom (2012: 9) «en la red es donde se ven más nuevas ideas de periodistas que creen que aún hay espacio para hacer ( ¡y vender!) su trabajo. Es un fenómeno reciente y cuesta aún acertar con algo que dé beneficios. La mayoría sólo tantea opciones. Pero hay algo que se mueve».

\section{La dedicación profesional a la Comunicación}

De todas las fuentes consultadas, la conclusión generalizada es que no existe un estudio lo suficientemente reciente ni representativo -aparte del informe que realiza todos los años la Asociación de la prensa de $\mathrm{Madrid}^{7}$ - de la situación formativa y laboral de los egresados en Comunicación en España. La mayoría de los estudios existentes datan de los primeros años del siglo XXI cuando la situación económica del país distaba mucho de la actual, donde la tasa de desempleo general es de $4.714 .122^{8}$ personas. Por tanto, resulta necesario un estudio nacional de la situación formativa y laboral de los profesionales de la Comunicación.

Si bien anteriormente hablábamos de un amplio período de transición desde la universidad hasta el mercado laboral, una vez llegados a éste, los licenciados vuelven a encontrarse con muchas trabas en su camino. Ser contratados como auxiliares administrativos, por un período de corta duración y con grandes diferencias horarias entre las contratadas y las trabajadas, son sólo algunos de los obstáculos que quienes «gozan» de un contrato remunerado tienen que solventar.

A este respecto no debemos olvidar las diferencias salariales entre los recién incorporados a los medios y los profesionales de reconocido prestigio. «Más de la mitad de los licenciados en Periodismo tiene una nómina mensual inferior a los 900 euros, nómina fácilmente superable por otras profesiones en las que no se exija una base de Licenciatura» (Caro González y Jiménez Marín, 2006: 319-322). El estudio de Bancaja (2002: 5) cifra los ingresos de los titulados en periodismo en 14.780 euros, muy lejos de otras profesiones que requieren una titulación superior.

6 Entrevista disponible en http://www.solobasket.com/contenidos/hoopshype/10/anos/biblia/nba/c-29332.html.

7 El Informe anual de la profesion periodística que realiza la APM del periodismo en su globalidad en España incluye un apartado con un análisis de la formación de los egresados en Comunicación en el país. Además recoge una encuesta sobre la autoestima de los profesionales y un estudio sobre la credibilidad de los medios.

8 Fuente: http://www.sepe.es/contenido/estadisticas/datos_avance/datos/datos_2012/AV_SISPE_1205.pdf 
La precariedad no sólo es aplicable al salario sino también a la situación contractual. Según el estudio citado anteriormente, los contratos indefinidos dentro de la profesión periodística apenas superan el 50\%.

Esta es la situación en la que se encuentran los recién licenciados que consiguen acceder al mercado laboral con un contrato. Situación que hace replantearse a muchos de los periodistas su sueño de trabajar en un gran medio de comunicación. Este desencanto lleva a muchos de estos licenciados/graduados a plantearse la creación de proyectos periodísticos independientes en los que no han de regirse ni por las normas políticas, económicas ni ideológicas de los grandes medios. Sirvan como ejemplos los portales que son objeto de estudio en este artículo.

\section{Planteamiento de la investigación, objetivos y metodología: estudio de caso}

Para Leopoldo Seijas (2001: 272) «el periodista digital es considerado "más que un redactor". Internet es un medio de comunicación "multimedia", es decir, tiene la capacidad de integrar texto, fotografía, vídeo y audio; por lo que los informadores deben concebir su trabajo desde una perspectiva multimedia, atendiendo a elementos de diseño del interfaz y de la estructura de contenidos» (en Rodríguez, 2011: 29). En nuestro caso se trata de conocer PEP y PDS, dos proyectos de Comunicación en la web, a través de sus creadores, nuevos periodistas digitales, quienes además darán cuenta de sus experiencias formativas así como de sus opiniones con respecto a las tendencias del mercado laboral emergente.

PEP y PDS comparten características. Ambos crean contenidos informativos textuales, visuales y audiovisuales, generando así una información original bajo un tratamiento semiprofesional y que tienen como medio de difusión Internet y las redes sociales. Se trata de portales web creados y gestionados por personas formadas en las Ciencias de la Comunicación, menores de 30 años que siguen formándose en su área de conocimiento.

Pero también, los dos proyectos periodísticos analizados difieren uno del otro. No sólo por su forma, gestión y dedicación, sino también por su configuración. De ahí que con el fin de conocer la esencia de los dos proyectos de micro y ciberperiodismo sea necesario el uso de técnicas de investigación. Por una parte, se ha llevado a cabo un análisis de contenido ${ }^{9}$ de ambos portales informativos, a través de una plantilla creada ad hoc con 148 variables siguiendo los parámetros propuestos por Nielsen $(2000,2007)$ y por Rosenfeld y Morville (2002). Por otra, se han realizado entrevistas en profundidad ${ }^{10}$ a los directores de los

9 En el análisis de contenido de los portales de PEP y PDS destacan variables y categorías como: niveles de profundidad de los portales, tipos de estructura general -jerárquica, lineal, lineal con jerarquía, red, marco o mixta-, alineación, equilibrio/asimetría, imágenes y fotografías, buscadores internos y externos, encabezados, migas de pan, vínculos, barra de navegación -estática, roll-over, menú emergente o menú desplegable-, lenguaje utilizado, legibilidad, corrección ortográfica, colores predominantes, tipografías, redes sociales.

10 Variables comunes a ambas entrevistas: definición del proyecto, fecha de creación, objetivos, personas que lo fundaron, nuevas incorporaciones, perfiles formativos y experimentales, proceso y criterios de selección, horas 
dos portales. Éstas han constado de dos partes: la primera de ellas, compuesta de preguntas generales y comunes a ambos proyectos; la segunda, de preguntas específicas, fruto del análisis de contenido realizado previamente y de las fuentes consultadas. Las entrevistas han sido administradas por correo electrónico y dirigidas a los directores de los dos proyectos periodísticos. Pasemos a conocer en profundidad sus características, elementos, estructuras y contenidos.

\subsection{Periodistas en potencia}

La estructura general de PEP es lineal ya que todos los elementos se encuentran albergados en el mismo nivel. Su organización se rige por criterios que tienen en cuenta al usuario. Anteponen el destinatario al valor corporativo.

En general, el máximo nivel de profundidad es el segundo pues aparece un primer nivel como home y los reportajes publicados se albergan en un segundo nivel a través de hipervínculos, que en lugar de mostrarse en subwebs, proceden de sus propios perfiles en las redes sociales que utilizan. Esto ocurre a excepción de determinados reportajes en los que insertan una imagen fija, ocupando ésta el tercer nivel.

PEP carece de mapa web, de página de ayuda, de visita guiada y del apartado «novedades» ya que señala la fecha de publicación del reportaje. Dado que las últimas noticias son las que ocupan la parte superior de la web, ordenadas temporalmente de las más recientes a las posteriores, de izquierda a derecha según el orden de lectura, hace innecesario la presencia del apartado novedades.

El proyecto de Sergio Barreda y Sandra Baraza ${ }^{11}$ es una página de frames a modo de marcos con diseño reticular y gran cantidad de espacios en blanco color de fondo de la web-alrededor de los textos que están centrados, en color negro y donde los hipervínculos aparecen en azul, el color corporativo de PEP. Prescinden de los ladillos pero sí utilizan los textos destacados en negrita. Los marcos de la página principal que albergan cada uno de los reportajes, así como todo su contenido -imagen, titular, breve resumen y fecha de publicación- funcionan como enlaces al reportaje en su totalidad, situado en un segundo nivel. Una vez se ha accedido al reportaje completo, la estructura habitual de elementos es la siguiente: título, subtítulo, imagen, cuerpo textual, reportaje audiovi-

dedicadas, funciones y relación contractual, forma jurídica, infraestructura disponible y fuentes de financiación, público y perfil sociodemográfico, tráfico del portal, gestión del trabajo diario, distribución de funciones, estrategias de difusión, publicidad y comercialización; necesidades formativas en el momento de creación del proyecto y actuales, asignaturas útiles y que menos han aportado. Variables específicas de PEP: constitución como asociación, tipo, fines y justificación, documental «Dos años de ilusiones y retos cumplidos», dossier propio, gestión del viaje a Málaga con motivo del reportaje del Festival de Cine e iniciativa de concurso de ideas del 2011. Variables específicas de PDS: redactores especializados por áreas temáticas, colaboradores especializados, caducidad de noticias en determinadas secciones, fuentes documentales, medios de referencia, gestión e infraestructura para grabación de vídeos así como gestión de los comentarios en el portal.

11 Barreda finalizó la licenciatura de Comunicación Audiovisual en la Universidad Jaume I de Castellón en 2011 y obtuvo una beca Séneca en la URJC donde actualmente realiza un máster. Baraza estudia Grado en Periodismo en la URJC y tiene previsto finalizar en 2013. 
sual procedente de Youtube, autores y colaboradores y, finalmente, aparecen los agradecimientos.

Al diseño limpio de PEP contribuye también la simetría y el equilibrio de los elementos, así como el hecho de que sea una web con reducido número de menús e inexistencia de submenús. Actualmente tan sólo existen los siguientes menús: equipo, agenda -que en la pregunta llevada a cabo en la entrevista sobre su utilidad, uso y frecuencia de actualización, contestaron que en la nueva versión de la web prevista para septiembre quedará eliminado- contacto y prensa. Quizás por este motivo la web tampoco incluya un buscador o motor de búsqueda interno o avanzado. Además, la navegación en PEP se realiza mediante barras roll-over.

Si analizamos los metadatos de la web ${ }^{12}$, comprobamos que como «title» aparece «Periodistas en potencia» y como «keywords» quedan posicionados con «Periodistas en potencia, reportajes, actualidad, música, periodismo, urjc».

\section{Imagen 1. Logotipo de PEP}

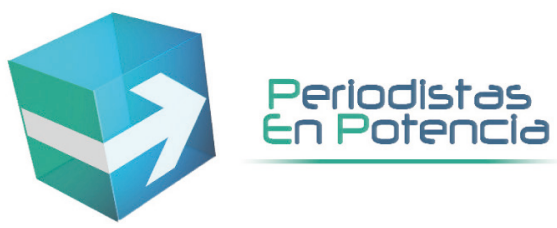

Fuente: www.periodistasenpotencia.es

En el logotipo de PEP - una figura abstracta en forma de cubo transparente con una flecha semi circundante- observamos que está presente en los dos niveles de la web a modo de encabezado y cuando el usuario se sitúa en el reportaje completo, puede volver a la página de inicio haciendo clic sobre éste. Esto hace innecesaria la presencia de las migas de pan $^{13}$, aunque para ello también existe el apartado «ver más reportajes». Si bien anteriormente indicábamos que los hipervínculos aparecen en el color corporativo principal de la web, el azul, la web no permite identificar con un color distinto -verde, por ejemplo, como el segundo color corporativo- los hipervínculos visitados, perdiendo así el usuario ventajas de lectura. El tratamiento del color en PEP es homogéneo: blanco como color de fondo, negro para los textos principales, azul para los titulares e hipervínculos. Éstos son los colores predominantes. Además, los hipervínculos no están subrayados.

12 Comprobados desde view-source:http://www.periodistasenpotencia.es/

13 Las migas de pan es un elemento de navegación y orientación que permite al usuario informarse constantemente del lugar en que se encuentra en la web. 
El lenguaje es cercano al usuario y los etiquetados, títulos y subtítulos son legibles así como el cuerpo textual. Únicamente escrita en español, en PEP respetan las normas ortográficas y gramaticales y se utiliza la fórmula idea por párrafo, lo que favorece que éstos sean de corta extensión. Además, la totalidad de vínculos analizados funcionan correctamente.

Si detenemos la mirada en las fotografías, observamos que acostumbran a aparecer una por reportaje -a su vez, es la misma instantánea que aparece como reclamo visual en la home-, ésta es correcta pues no aparece deformada, su resolución es apropiada, permite su ampliación y descarga, guarda relación con el acontecimiento y se asocia con la idea principal del reportaje, pero no aparece acompañada de pie de foto.

Los vídeos de $P E P$-el principal atractivo de la web y de sus reportajes- como ya consta en este artículo, proceden de Youtube, lo que permite al destinatario su control de visionado y sonido. Además, éstos no incluyen publicidad.

Un hecho destacable en PEP es la diferencia de las respuestas vertidas en las entrevistas -ofrecidas el 13 de junio-y los resultados del análisis de contenido que nos ocupa. Estas diferencias proceden del contenido publicitario de la web. Sergio y Sandra indicaban que no difundían publicidad. Pero en el momento en que se escriben estas líneas -29 de junio de 2012- se observa un banner de www.piensasolutions.com, un servicio de hosting y servidores, que posiblemente sea el que albergue a PEP. Quizás el perfil de la nueva incorporación al equipo $P E P$ venga a cubrir las necesidades publicitarias de la web y posiblemente también una de las primeras tareas que tenga sea encontrar un eslogan porque, a diferencia de Portal del Sur, Periodistas en potencia, carece de él.

Atendiendo a aspectos relacionados con las tipografías utilizadas, el logotipo de PEP es de palo seco, mientras que el resto de tipografías de títulos, subtítulos y cuerpos textuales son romanas con serifa.

Si nos fijamos en la proporción imagen/texto, observamos que en la parte superior de la home predominan las imágenes. Efecto contrario ocurre en la parte inferior de ésta y en los reportajes completos de segundo nivel.

El dominio de PEP [www.periodistasenpotencia.es] está registrado y hace uso de las siguientes redes: Facebook, Twitter, GooglePlus y Youtube. Además, utiliza los botones «Me gusta», «Tweet» $\mathrm{y} «+1 »$.

Carece de un enlace permanente del tipo «trabaja con nosotros». Aunque en la entrevista afirman que realizan llamadas desde su web en el momento en que necesitan nuevas incorporaciones. Pero, en cambio, sí existe la posibilidad de contactar con cada uno de ellos, no sólo a través de correo electrónico, sino también por teléfono móvil. 
La web permite, previo registro de los usuarios, que éstos dejen constancia de sus opiniones y comentarios, dando pie al feedback y a la expresión de la opinión pública.

Por último, PEP dispone de una licencia vigente ya que todos sus derechos están reservados para 2012.

\subsection{Portal del Sur}

PDS es un dominio .es (www.portaldelsur.es) identificable y significativo, cuya especialidad temática es la información local que se actualiza diariamente entre semana a excepción de acontecimientos muy relevantes que tienen lugar durante el fin de semana y que se publican desde casa. Tiene una estructura general de tipo lineal con jerarquía. Así, en un primer nivel aparecen las diferentes localidades englobadas en el portal y a su vez, cada una de ellas tiene un submenú con secciones. El criterio de organización que sigue la web está centrado en el usuario y tiene una profundidad general de tres niveles: 1 home, 2 población, 3 noticia. Y alberga «noticias, madrid, local, noticias del sur» ${ }^{14}$ como metadatos.

En un análisis general, el portal tiene un rótulo de encabezado o logotipo que aparece en todas las páginas y niveles quedando suficientemente destacado en la parte superior izquierda de la página. Además actúa como enlace a la home. Se identifica la fecha de creación de cada una de las noticias alojadas en la web y los contenidos novedosos pueden verse a través del apartado últimas noticias.

\section{Imagen 2. Logotipo de PDS}

\section{PortaldeISur.es \\ Haznos tus faworltos}

Fuente: www.portaldelsur.es

Por otra parte, la barra de navegación es un menú emergente, ya que al pinchar en un enlace se abre el submenú. Además, hay iconos que funcionan como hipervínculos. La mayor extensión de la página está dedicada a las noticias o contenidos de interés. PDS cuenta con un buscador interno de noticias en el que el criterio de búsqueda puede ser una palabra clave o una frase exacta. En la portada destaca la escasez de blancos, lo que da cierto aspecto de apelmazamiento. Además, el fondo de la página es blanco. El énfasis predominante es vertical y tiene un equilibrio simétrico. Cumple el modelo de pirámide invertida ya que las noticias publicadas van de lo general a lo específico.

14 Comprobados desde view-source:http://www.portaldelsur.es/ 
A nivel cromático, los vínculos sobre textos no están subrayados pero sí tienen una convención de colores. De esta forma, la tipografía utilizada en los textos es de color negro, mientras que la que se usa en los titulares es de color azul y se torna roja cuando se sitúa el cursor encima, ofreciendo al usuario ventajas de lectura y consulta. Sin embargo, no utiliza ningún color corporativo en la web ni usa ningún tipo de connotaciones cromáticas para separar apartados o secciones. De esta forma, el color no interfiere en la visualización de la información contenida en la web. El tratamiento cromático, por tanto, es homogéneo en todas las secciones y subapartados.

Los textos tienen un lenguaje cercano al usuario y la legibilidad de los títulos, subtítulos y cuerpo textual es adecuada. Utiliza rótulos estándar y todos los vínculos que aparecen funcionan correctamente. Existen vínculos del tipo «leer más» en todas las informaciones.

En cuanto al análisis de las noticias se refiere, la media de palabras por título ronda las 15, mientras que en los subtítulos la media sube hasta las 25 palabras. En el cuerpo textual carece de sentido calcular una media ya que existen noticias de gran relevancia que superan las 1.000 palabras y otras que son simplemente breves de apenas 50. La web respeta las normas ortográficas y gramaticales y utiliza un lenguaje correcto. En las redacciones destacan los textos largos y el uso de la narración fragmentada de forma que se distribuye una idea por párrafo y no se emplean ladillos.

En PDS tiene gran relevancia el contenido visual -de hecho cuenta con varias galerías fotográficas- y además, la mayoría de las noticias están ilustradas por una imagen, pero no tiene un número de instantáneas estipulado. El tamaño de las imágenes no es correcto ya que, al menos, al visualizar la página con los navegadores Internet Explorer o Google Chrome, muchas de las fotografías aparecen cortadas. La resolución sí es la adecuada y no existen fotografías pixeladas. La mayoría de las fotografías son informativas y aportan un contenido extra a la información que contiene el texto. Además, ofrece al usuario la posibilidad de ampliar la fotografía o descargársela si lo desea. Todas cuentan con un pie de foto explicativo y se asocian claramente con la noticia a la que aluden, aunque no están vinculadas mediante link a ningún texto. PDS carece de imágenes en movimiento.

La web cuenta con la presencia de vídeos alojados en Youtube. No tienen publicidad y pueden ser controlados por el usuario mediante los botones de play, pausa y stop. Los vídeos aportan contenido extra, no relacionado con ningún texto. Sin embargo, la web no contiene archivos exclusivamente sonoros ni archivos de textos en formato .pdf o .doc.

Puesto que una de las formas de financiación de PDS es la publicidad, resulta lógico que la página cuente con gran variedad de banners publicitarios. En todos los casos está justificado su empleo y funcionan correctamente. Se trata de publicidad de instituciones públicas y empresas privadas, tanto de productos 
como de servicios. También utiliza banners a modo de publicidad corporativa y autopromoción de la web a través de su eslogan «Otro tipo de información es posible». No obstante, a pesar de recibir ingresos publicitarios, la licencia de PDS está caducada desde 2010-2011.

Por otra parte, PDS sólo está disponible en un idioma: español. Utiliza tipografía de palo seco y su tamaño varía en función del lugar que ocupa dentro de la home, o si se trata de un titular, un subtítulo o un cuerpo textual.

El portal está presente en redes sociales (Facebook, Twitter, Youtube y Flick). Incluye el icono de RSS y otros como «Me gusta» o «Twittear». Además, ofrece al usuario la posibilidad de ponerse en contacto con los responsables a través de un email de la propia web (redacción@portaldelsur.es) e incluso es posible comentar las noticias pero no suscribirse a las mismas. A pesar de esta posibilidad brindada al usuario, el feedback observado es muy reducido ya que apenas hay comentarios.

\section{Análisis de las entrevistas en profundidad realizadas a los promotores de ambas webs}

\subsection{Periodistas en Potencia}

PEP es un proyecto de micro y ciberperiodismo cultural dirigido por Sergio y Sandra, que mantiene la forma jurídica de Asociación Juvenil de la Comunidad de Madrid y que «comenzó como una manera de expresarnos fuera de las aulas, como una forma de poner en práctica lo que estábamos aprendiendo». Sus orígenes datan de enero de 2010 y proceden de un blog con inclusión de reportajes audiovisuales -el primero de ellos realizado en torno a la Feria Internacional de Turismo-. Conocedores de que su contenido audiovisual les resta tráfico web, siguen apostando por la calidad de los reportajes más que por la cantidad de receptores. Aún así cuentan con 387 fans en Facebook, 1.937 seguidores en Twitter y 69 suscriptores en Youtube ${ }^{15}$.

Por una parte, de las necesidades formativas y expresivas iniciales, los 17 chicos que conforman a día de hoy PEP - ya han pasado por este proyecto de comunicadores 22 redactores, técnicos y reporteros- han ido incluyendo otros objetivos como «mejorar en el trabajo en equipo, conocer nuevos aspectos de la comunicación, perfeccionar técnicamente, establecer contactos dentro del mundo de la comunicación, networking con otros profesionales...». Por otra, de su formación universitaria valoran positivamente los conocimientos adquiridos en relación a la redacción, el periodismo multimedia, la empresa audiovisual, la televisión y la radio. No tanto como los sociológicos y jurídico-legales.

Su perfil es el de jóvenes estudiantes y/o licenciados en Periodismo y en Comunicación Audiovisual, entre 19 y 24 años que se dedican a PEP de forma parcial

15 Datos obtenidos con fecha 13 de junio del 2012. 
o esporádica y no remunerada. Y que utilizan y comparten materiales y recursos autofinanciados (cámaras, micrófonos y grabadoras). Cuando el proyecto esté consolidado, no descartan utilizar técnicas mixtas como los reportajes patrocinados con el fin de conseguir una financiación externa, aunque tampoco descartan ser absorbidos por un grupo editorial, siempre y cuando esto no les suponga cambiar la línea editorial.

En el momento en que se escriben estas líneas -junio de 2012- están inmersos en el proceso de selección de nuevos colaboradores para la cuarta temporada que comenzará en septiembre u octubre con una nueva web. Como criterios de selección no usan el bagaje curricular sino «el conocimiento del proyecto y las ganas de formar parte de él». En parte porque están convencidos de que «el mayor beneficio es el aprendizaje profesional y gestionar nuestro propio proyecto».

Si en Internet ven tanto la base del proyecto y de su trabajo, como el medio que soporta a ambos, en las redes sociales proyectan la principal herramienta de promoción de PEP. Destacan que los «factores de Internet como la multimedialidad, interacción, feedback están muy presentes en nuestro proyecto». Porque aún cuando se dedican principalmente a realizar reportajes audiovisuales, no reúsan redactar noticias que acompañan a los reportajes, posicionan la web y dan cabida a los comentarios de sus seguidores. Internet es el medio de PEP y quizás sin ser conscientes, el soporte de su currículum. «Ahora lo tenemos más fácil que nunca para mostrar nuestro trabajo al mundo real».

Los jóvenes desempleados y con escasas oportunidades laborales ven en el emprendimiento una inversión de futuro y un trampolín hacia una mejora profesional, pero son pocos los que llegan a crear, y más aún mantener, un proyecto empresarial. «Emprender se lleva dentro. No es algo que se aprenda, se nace ya con ello. Una de las cosas más importantes es la actitud». Ésta es la opinión de quienes a pesar de no recibir ninguna remuneración económica por su trabajo ni formar parte de una empresa informativa como tal, aspiran y consiguen cubrir actos aparentemente reservados a profesionales consagrados, tales como la gala de los Goya o el estreno de la última película de Mario Casas.

\subsection{Portal del Sur}

PDS es un proyecto de periodismo digital de cercanía que engloba a once municipios de la zona sur de Madrid ${ }^{16}$. Está formado por jóvenes periodistas, muchos de ellos recién graduados, que ofrecen información especializada en municipios más que en temáticas, convirtiéndose así en un lugar donde el lector puede encontrar información pormenorizada de diferentes ámbitos dentro de una misma localidad, desde política hasta deportes, pasando por la agenda cultural y las notas de sociedad.

16 Pozuelo de Alarcón, Aranjuez, Cienpozuelos, Fuenlabrada, Getafe, Leganés, Móstoles, Parla, Pinto, San Martín de la Vega y Valdemoro. 
PDS es un proyecto periodístico reciente aunque «con pretensiones de que sea duradero» que surgió en mayo de 2010 de la mano de Casandra López ${ }^{17}$, su directora, que tras terminar los exámenes finales se planteó crear una web de ámbito informativo «como una manera de revelación ante los grandes medios que explotan a los alumnos sin enseñarles nada». Así, como una forma de autoaprendizaje y con el objetivo de «sobrevivir a la crisis sin perder el rigor periodístico», la idea emergente, que tuvo como fuente de inspiración y motivación a «un profesor de Opinión Pública que nos machacaba una y otra vez con la idea de los periodistas como meros altavoces», se afianzó en enero de 2011.

Se trata de una SLNE ${ }^{18}$ que está ubicada en Pinto (Madrid) y que ofrece información de tipo local y comarcal a un «target de clase media/baja de entre 16 y 55 años». Cuenta con el respaldo del grupo empresarial Rochasociados\&Consulting, cuyo presidente es su editor. En apenas dos años de vida la web ha pasado de contar con el equipo primigenio formado por dos personas, a un grupo de siete trabajadores en plantilla más colaboradores y alumnos en prácticas. A pesar del incremento de personal experimentado en la corta vida de la web, actualmente reconocen que el crecimiento se encuentra estancado y que no están realizando ninguna prueba de selección.

La empresa se estructura en torno a un organigrama vertical, aunque tiene «muy en cuenta las opiniones de los unos y de los otros». El grueso de la plantilla tiene edades comprendidas entre los 24 y los 29 años. Hay cinco hombres y dos mujeres. En cuanto a la situación laboral, tres de ellos tienen contrato de jornada completa mientras que los tres restantes dedican 25 horas semanales a la web. Cabe destacar que cuatro de los trabajadores están recién licenciados y siguen estudiando o tienen intención de hacerlo durante el presente año, con el objetivo de completar su formación académica a través de un máster.

Los periodistas de PDS compaginan su trabajo en la web con pequeñas y esporádicas colaboraciones dentro del ámbito periodístico. Además, una de las redactoras también trabaja en una tienda y Casandra, la directora, realiza en ocasiones actividades de tipo audiovisual que le son encargadas por terceras personas.

El modus operandi de PDS está basado en fuentes primarias ya que no tienen contratado ningún servicio de agencias. Internet «es fundamental» para su día a día. «Es una ventana única para que nuestro público conozca nuestras noticias». Además, se nutren de las redes sociales para llegar a un sector más amplio de la población. Así, cuentan con 1.813 fans en Facebook y 867 seguidores en Twitter ${ }^{19}$.

\footnotetext{
17 Licenciada en Periodismo por la URJC en mayo de 2011, perteneciente a la promoción 2006-2011.

18 Sociedad Limitada Nueva Empresa.

19 Datos del 13 de junio del 2012.
} 
Los redactores trabajan desde casa y se reúnen de forma habitual en las oficinas que su grupo editor les ha cedido. Además, del respaldo económico del grupo Rochasociados, otra de las fuentes de financiación de PDS es la publicidad. La web se da a conocer a los anunciantes a través de reclamos situados en la portada de la misma. También cuentan con la colaboración de comerciales que visitan a los diferentes clientes para ofrecerles el producto. El precio de los banners depende de su ubicación dentro de la página y de su tamaño. El proyecto tiene unos costes fijos de 1.500 euros mensuales, y por el momento, los beneficios obtenidos «sólo dan para cubrir gastos». Los redactores cuentan con un sueldo fijo y los materiales que utilizan para realizar su trabajo diario han sido aportados por el grupo empresarial al que pertenecen.

Atendiendo al ámbito académico-formativo, los jóvenes periodistas que recién titulados entraron a formar parte de la plantilla de PDP coinciden en destacar «Tecnologías multimedia» y «Redacción periodística» como las asignaturas que más les ayudaron para introducirse en el mundo del periodismo digital. Mientras que «Fundamentos de la Publicidad y las RRPP» es la asignatura a la que menos rendimiento laboral le encuentran. Más allá de los contenidos meramente académicos relacionados con el periodismo en sí, subrayan la falta de contenidos prácticos en la formación universitaria. Uno de los aspectos que destaca Casandra es el desconocimiento de las pautas para crear una iniciativa empresarial. «Me hubiera gustado saber más en cuanto al tema de las subvenciones, ya que al no saber donde dirigirte pierdes muchas ayudas y en este sentido nadie te echa una mano».

Los profesionales de PDS se muestran satisfechos con el trabajo realizado aunque «hay aspectos que se podrían mejorar». La clave está en «ofrecer una información diferente y objetiva, que permita al lector formarse su propia opinión». Además, fueron los primeros en ocupar el nicho de mercado en el que desarrollan su labor y aunque ahora hay otros medios que cubren informativamente las mismas zonas geográficas, ninguno se encuentra tan asentado.

A pesar de ser un medio digital, también cuenta con una revista en formato papel. Por el momento sólo se ha impreso un número a modo de reclamo publicitario. Se trató de un número gratuito distribuido en lugares estratégicos como estaciones de tren, bibliotecas o centros de salud y a través de un pequeño buzoneo en zonas seleccionadas. «La intención es que la periodicidad sea cuatrimestral. Y si es en formato papel o digital, vendrá dado por los anunciantes, aunque nosotros somos digitales y nuestro negocio está en el digital».

Definen la situación del mercado de la comunicación como «mala» y destacan que el principal reto al que se enfrenta el periodismo a día de hoy es «adaptarse a los nuevos tiempos y no temer a las nuevas herramientas tecnológicas». Sólo de esta forma es posible lograr uno de sus objetivos a medio plazo: conseguir beneficios y llegar a ser autosuficientes. 


\section{Conclusiones y discusión}

Podemos afirmar que en base al análisis realizado, existe una relación entre la edad de las personas vinculadas a ambos proyectos periodísticos y su adhesión formal a estos. Si bien cuando son menores de 24 años, no existe relación contractual con el proyecto, a medida que avanza su edad se formaliza su vinculación, no ya a una asociación, sino a una empresa.

Aún así, en ninguno de los casos son autosuficientes ni generan beneficios, teniendo en cuenta que PEP ni siquiera genera ingresos. Esto, a su vez, guarda relación con la inclusión de publicidad en sus portales y los costes fijos que genera la plantilla de $P D S$.

En materias universitarias, los miembros de ambos portales, destacan contenidos o asignaturas relacionadas con el Periodismo. En ningún momento con la Comunicación Audiovisual -aún cuando ambos hacen uso de la imagen en movimiento- y menos aún con la Publicidad y las Relaciones Públicas. En cuanto a las carencias formativas, destacan las principales lagunas, los idiomas y las habilidades directivas. No obstante, siguen formándose y los dos proyectos analizados utilizan a becarios y colaboradores. Si bien PEP gestiona la incorporación de estos, en PDS es una persona que tiene lejana su formación universitaria -no relacionada con las Ciencias de la Información- la que realiza la selección de personal. Ambos ven en sus proyectos un trampolín profesional.

Por otra parte, resulta fundamental el período de transición del egresado en Comunicación ya que son muy pocos los que directamente dan el paso de la facultad a la redacción. Lo lógico es que los recién egresados empleen un período de transición que, en ocasiones, puede alargarse durante varios años, durante el cual realizan labores de becarios, colaboradores, periodistas semiprofesionales no remunerados, blogeros y cuando se unen, lo hacen bajo la forma jurídica de la asociación. Así, el período de formación no puede relegarse únicamente a los años empleados en los estudios académicos, sino que hay que unir todo el tiempo destinado a la autoformación fuera ya de la comunidad universitaria.

PDS tiene una naturaleza más empresarial. Por el contrario, PEP es más una dedicación altruista, asociativa y no remunerada. Este hecho no guarda relación con el resultado final de la información publicada, pues PEP cuida más la estética, la forma y la calidad. Recordemos en este sentido las fotografías recortadas de $P D S$ y el aspecto de apelmazamiento.

Ambos proyectos convergen en el uso de las redes sociales con un triple objetivo: mantener informado a su público habitual, llegar a un público diferente al que darse a conocer y la reducción de costes en cuanto a la sustitución de servidores propios para alojar videos e imágenes por el uso de las RRSS.

Aún viviendo en el seno de una sociedad democrática y libre, la situación precaria, económica y laboral, favorece el control y el sometimiento ideológico de los periodistas. En muchas ocasiones, las informaciones redactadas en primera 
instancia deben pasar el filtro ideológico de la directiva antes de ser publicadas. En otros casos, los periodistas ya están suficientemente aleccionados sobre qué temas y personas pueden o no aparecer en los medios. En cualquier caso, alguna de las bases del periodismo, como la objetividad y la denuncia pública de determinadas situaciones, quedan relegadas si entran en conflicto con los intereses de las altas instancias. En este sentido, de los casos estudiados, tan sólo PEP no pertenece a ningún grupo empresarial y, por tanto, no se ven condicionados ni ideológica ni editorialmente por intereses ajenos al rigor y a la ética periodística. No obstante, los profesionales de PDS, a pesar de estar respaldados por el grupo Rochasociados, no reconocen en ningún momento tener ningún tipo de presión ni de control a la hora de publicar o no cualquier tipo de información.

Por último, cabe destacar el papel vertebrador de Internet en todo este proceso. De esta forma, los licenciados/graduados en Comunicación pueden llegar a publicar sus creaciones con un coste mínimo y comenzar así a crearse un nombre en el arduo desempeño de la labor periodística. Sin Internet, este hecho sería imposible ya que estos jóvenes periodistas no cuentan con las condiciones económicas necesarias para crear un medio de comunicación fuera de la red. A su vez, estos jóvenes, nativos en la red, cuentan con una ventaja comparativa con respecto a los medios tradicionales que han tenido que adaptar sus formatos y formas de trabajo a la era digital.

En definitiva, estos dos proyectos predicen que la vocación periodística está por encima de la coyuntura actual. También ayuda que los jóvenes no han necesitado habituarse a las nuevas tecnologías ya que desde un primer momento han nacido con ellas.

\section{Referencias}

Agencia Nacional de Evaluación de la Calidad y Acreditación (ANECA) (2005). Libro Blanco. Títulos de Grado en Ciencias de la Comunicación. En: http:// www.aneca.es/var/media/150336/libroblanco_comunicacion_def.pdf [Consultado el 1 de junio de 2012].

Asociación de la prensa de Madrid (APM) (2011). Informe Anual de la Profesión periodística. Madrid.

Bancaja (2002). La situación laboral de los graduados españoles. En: Capital Humano, n. 21, julio. En: http://obrasocial.bancaja.es/publicaciones/publicaciones-ficha.aspx?id=46 [Consultado el 2 de junio de 2012].

Caro González, Francisco Javier y Jiménez Marín, Gloria (2006). Periodistas: el acceso al mercado laboral. En: Ámbitos, $\mathrm{n}^{\circ}$ 015. Sevilla: Universidad de Sevilla 313-234. En: http://redalyc.uaemex.mx/redalyc/html/168/16801517/16801517. html [Consultado el 2 de junio de 2012]. 
Domínguez Martín, Eva y Pérez Colom, Jordi (2012). Microperiodismos: Aventuras digitales en tiempos de crisis. Barcelona: UOC. En: http://books.google. es/books?hl=es \&lr=\&id=whDsB1bEj0C\&oi=fnd \&pg=PA13\&dq=microperiodism o\& ots=9ZJtnAv hh7\&sig=ZWqKvdNlr6ghxzd6o43SV crfFl4\# $\mathrm{v}=0$ nepage \&q=micr operiodismo\&f=false. [Consultado el 2 de junio de 2012].

El País, sancionado por las condiciones laborales de sus becarios. En: Equipos y talento: http://www.equiposytalento.com/noticias/2012/02/13/el-pais-sancionado-por-las-condiciones-laborales-de-sus-becarios [Consultado el 27 de junio de 2012].

Instituto Nacional de Estadística (INE) (2012). Enseñanza universitaria 1er y $2^{o}$ ciclo. Estudios de Licenciatura por tipo de presentación, profesorado, alumnado matriculado que terminó los estudios y curso académico. En: http:// www.ine.es/jaxi/tabla.do?path=/t13/p405/a2010-2011/10/\&file=01008.px\&type $=$ pcaxis $\& \mathrm{~L}=0$ [Consultado el 8 de junio de 2012].

Monje, Andrés (2012). Jorge Sierra, el alma de HoopsHype, es entrevistado por Solobasket con motivo del décimo aniversario del proyecto, actualmente una de las webs más prestigiosas del mundo NBA. En Solobasket http://www.solobasket.com/contenidos/hoopshype/10/anos/biblia/nba/c-29332.html [Consultado el 9 de junio de 2012].

Nielsen, Jacob y Loranger, Hoa (2007). Usabilidad. Prioridad en el diseño web. Madrid: Anaya Multimedia.

Nielsen, Jacob (2000). Usabilidad. Diseño de sitios web. Madrid: Pearson Educación.

Pérez de Pablos, Susana. (2005). ¿Qué opinan las empresas de los recién licenciados. En El País, jueves, 24 de febrero de 2005. En: http://elpais.com/ diario/2005/02/24/sociedad/1109199604_850215.html [Consultado el 2 de junio de 2012].

Rodriguez, Pepe (2011). Ciberperiodismo, pseudoperiodismo y tráfico de información en la web 2.0: definiciones, riesgos y responsabilidades. En: II Congreso sobre las Nuevas Tecnologías y sus repercusiones en el seguro: Internet, Biotecnología y Nanotecnología. En: http://fundacionmapfre.com/ccm/content/ documentos/fundacion/cs-seguro/libros/II-Congreso-Nuevas-Tecnologias-y-surepercusion-en-el-seguro.pdf\#page $=29$ [Consultado el 10 de agosto de 2012] .

Rosenfeld, Louis y Morville, Peter. (2002). Arquitectura de la información para el $W W W$. Mexico: McGraw-Hill.

Servicio Público de Empleo Estatal (SEPE) (2012). Datos de los registros del Servicio Público de Empleo Estatal. Demandantes de empleo, paro, contratos y prestaciones por desempleo. En: http://www.sepe.es/contenido/estadisticas/ datos_avance/datos/datos_2012/AV_SISPE_1205.pdf [Consultado el 27 de junio del 2012]. 


\section{Referencia de este artículo:}

Segarra Saavedra, Jesús; Páramo Galdón, Patricia y Puebla Martínez, Belén (2012). Jóvenes emprendedores y sus proyectos de Comunicación en la red: estudio de caso de Periodistas en potencia y Portal del Sur. En: adComunica. Revista Científica de Estrategias, Tendencias e Innovación en Comunicación, $\mathrm{n}^{0} 4$. Castellón: Asociación para el Desarrollo de la Comunicación adComunica, Universidad Complutense de Madrid y Universitat Jaume I, 39-61. DOI: http:// dx.doi.org/10.6035/2174-0992.2012.4.4 